\title{
COMPARISON OF SYNCHRONISATION AND FERTILITY AFTER DIFFERENT MODIFICATIONS OF THE OVSYNCH PROTOCOL IN CYCLIC DAIRY COWS
}

\author{
Gulnaz YilmaZBAS-MeCitoglu ${ }^{1}$, Ebru KaRAKaYA ${ }^{1}$, Abdulkadir KeSKIN ${ }^{1}$, \\ Ahmet GUMEN $^{1 *}$, Volkan Koc ${ }^{2}$ and Hayrettin OKUT ${ }^{3}$ \\ ${ }^{1}$ Department of Obstetrics and Gynaecology, Faculty of Veterinary Medicine, University \\ of Uludag, Görükle, Bursa 16059, Turkey; ${ }^{2}$ Tarfas Company, Karacabey, Bursa, Turkey; \\ ${ }^{3}$ Department of Biometry and Genetics, Faculty of Agriculture, University of Yuzuncu \\ Yil, Van, Turkey
}

(Received 22 June 2012; accepted 11 December 2012)

\begin{abstract}
The objectives of this study were to evaluate the effects of (1) double doses of $\mathrm{PGF}_{2 \alpha}$ administration or (2) an exogenous progesterone (CIDR) applied concurrently with, or (3) the day after, first GnRH of Ovsynch (GnRH-1), on synchronisation and fertility during the Ovsynch protocol. All cows $(\mathrm{n}=378)$ received the Ovsynch protocol (GnRH-7d-PGF $\left.F_{2 \alpha}-56 h-G n R H-18 h-T A I\right)$. The 'OVS' group $(\mathrm{n}=105)$ received only the Ovsynch protocol. The 'OVS-PGF' group $\left(\mathrm{n}=118, G n R H-7 d-P G F_{2 \alpha}-12 h-P G F_{2 \alpha}-44 h-G n R H-18 h-T A I\right)$ received an extra dose of $\mathrm{PGF}_{2 \alpha} 12 \mathrm{~h}$ later on Day 7. The 'OVS-7CIDR' group (n $=78, G n R H+C I D R-$ $\left.7 d-P G F_{2 \alpha}-56 h-G n R H-18 h-T A I\right)$ received a CIDR for 7 days between GnRH-1 and $\mathrm{PGF}_{2 \alpha}$. In the 'OVS-6CIDR' group ( $\mathrm{n}=77, \mathrm{GnRH}-24 h-C I D R-6 d-P G F_{2 \alpha}-56 h-$ GnRH-18h-TAI), CIDR was applied one day after GnRH-1 and removed 6 days later. When all cows were evaluated, the responses to GnRH-2 were higher ( $\mathrm{P}=$ $0.005)$ in cows that responded to GnRH-1 (95.4\%) compared to the cows that did not respond $(87.6 \%)$. The pregnancy rates at 31 and 62 days for each group were $48.6 \%$ and $42.9 \%$ in the OVS, $54.2 \%$ and $52.5 \%$ in the OVS-PGF, $52.6 \%$ and $48.7 \%$ in the OVS-7CIDR, and $55.8 \%$ and $49.3 \%$ in the OVS-6CIDR groups. Thus, none of the three different treatments has an effect on increasing the outcomes of the Ovsynch protocol in cyclic lactating dairy cows.
\end{abstract}

Key words: Cow, Ovsynch, CIDR, double-PGF $2 \alpha$, synchronisation

The Ovsynch protocol is an effective breeding programme used in lactating dairy cows worldwide. The protocol involves the following three hormone administrations: a GnRH administration (GnRH-1) on day 0 , followed by $\mathrm{PGF}_{2 \alpha}$ administration on day 7, and another administration of GnRH (GnRH-2) $48 \mathrm{~h}$ later (Pursley et al., 1995). The administration of these hormones synchronises

*Corresponding author; E-mail: agumen@uludag.edu.tr; Phone: 0090 (224) 294-0824; Fax: 0090 (224) 294-1202 
the initiation of a follicular wave by ovulation of an ovulatory follicle, the regression of the corpus luteum and eventually, the ovulation of the dominant follicle of the new follicular wave. This precise synchronisation of ovulation within an 8-h period, 24-32 h after the administration of GnRH-2, allows for successful timed artificial insemination (TAI) without any oestrus detection. Therefore, the success of the Ovsynch protocol dramatically depends on the responses to these hormones. With respect to the response to GnRH administrations, fertility is better in cows that respond to the GnRH-1 in the Ovsynch protocol compared to those cows that do not respond (Vasconcelos et al., 1999; Moreira et al., 2001; Bello et al., 2006; Galvao and Santos, 2010; Keskin et al., 2010). Similarly, Galvao and Santos (2010) reported that any application that increases ovulation in response to GnRH-2 should result in increased fertility. For instance, administering exogenous progesterone (CIDR) between the GnRH-1 and PGF $_{2 \alpha}$ treatments is a modification of the Ovsynch protocol that is reported to increase the response to GnRH-2 and may therefore improve pregnancy rate (Stevenson et al., 2006; Galvao and Santos, 2010). However, another study showed that the administration of exogenous progesterone during the Ovsynch protocol decreases the response to GnRH-1 because of the possible negative feedback effect of progesterone on LH secretion (Galvao et al., 2004). Thus, any attempt to eliminate the possible negative effect on the response to GnRH-1 during progesterone administration, based on the Ovsynch protocol, may result in a higher response to $\mathrm{GnRH}$ administration and a higher pregnancy rate. As far as we know, there is only one study that evaluated pregnancy rate after the protocol in which CIDR was applied the day after GnRH-1 (not concurrently). Nevertheless, that study did not provide an opportunity to evaluate the constituents of synchronisation (responses to hormone administrations) during the protocol (Pancarci et al., 2008). In our study, we aimed to evaluate the effects of using different timings of CIDR during the Ovsynch protocol on synchronisation (responses to GnRH-1, GnRH-2, early ovulation before TAI and no ovulation after TAI) and fertility (pregnancy per AI) in lactating dairy cows.

In addition to the importance of the cow's responses to GnRH administrations, the response to $\mathrm{PGF}_{2 \alpha}$ administration also has a critical role in successful synchronisation during the Ovsynch protocol by providing regression of the corpus luteum. Previous studies have shown that ensuring complete luteal regression shortly after $\mathrm{PGF}_{2 \alpha}$ administration induces a greater response to GnRH-2 (Moreira et al., 2001; Galvao and Santos, 2010). It is also known that the percentage of cows that do not have complete luteolysis, as a response to the $\mathrm{PGF}_{2 \alpha}$ in the Ovsynch protocol, is rather high, up to 20\% (Moreira et al., 2001; Gumen et al., 2003; Brusveen et al., 2009). Those cows that do not respond to PGF2 $\alpha$ had approximately only a 5\% chance of pregnancy (Martins et al., 2010). Because providing complete luteolysis after $\mathrm{PGF}_{2 \alpha}$ administration is substantial to optimize synchronisation during the Ovsynch protocol, some studies have evalu- 
ated the effects of different $\mathrm{PGF}_{2 \alpha}$ products or additional doses of $\mathrm{PGF}_{2 \alpha}$ on improving luteolysis (Brusveen et al., 2009; Martins et al., 2010). Although it is reported that using different $\mathrm{PGF}_{2 \alpha}$ products had no effect on luteolysis (Martins et al., 2010), Brusveen et al. (2009) reported that the administration of two doses of $\mathrm{PGF}_{2 \alpha}$ successfully increased the percentage of cows that had complete luteal regression. In our study, we also aimed to evaluate the effect of an additional dose of $\mathrm{PGF}_{2 \alpha}$ on Ovsynch outcomes.

Thus, the objectives of the present study were to compare the effects of (1) using double doses of $\mathrm{PGF}_{2 \alpha}$ and (2) using a CIDR applied concurrently with, or (3) the day after, GnRH-1 administration on synchronisation and fertility during the Ovsynch protocol.

\section{Materials and methods}

Cyclic lactating dairy cows $(\mathrm{n}=506)$, at $125 \pm 5.0$ days in milk (DIM) on average, from a commercial dairy farm included a total of 1200 dairy cows, located in the South Marmara region, Bursa, Turkey, were enrolled in the present study. The experiment was carried out between December 2010 and July 2011, when the average monthly temperature ranged between 5.6 (January) to $26.1{ }^{\circ} \mathrm{C}$ (July). Cows were housed in free stall barns with self-catching headlocks, and all barns had fans and sprinklers that were activated during the hotter months of the year. All cows were grouped according to their milk production and were milked three times daily at approximately 8 -h intervals. The mean milk production of the herd was $9880 \pm 69.7 \mathrm{~kg}$ (305 days) per cow. Cows had free access to water and were fed complete mixed rations according to the National Research Council recommendations (2001). Daily milk yield, reproductive health and management records for each cow were collected from Alpro 2000 (DeLaval, Sweden). The average milk production for each cow was recorded from the 7th day before and after AI. Body condition scores (BCS) were determined for all cows at the time of GnRH-1 treatment of the Ovsynch protocol using a 5-point $(1=$ thin to $5=$ fat $)$ scoring system (Ferguson et al., 1994). All protocols involving cows used in this research were approved by the Animal Care Committee of the Lalahan Livestock Central Research Institute.

Cyclic cows $(n=506)$ were randomly assigned to the following four groups: Control (OVS, $\mathrm{n}=124)$, Ovsynch-PGF ${ }_{2 \alpha}($ OVS-PGF, $\mathrm{n}=132)$, Ovsynch-7CIDR (OVS-7CIDR, $n=133$ ), and Ovsynch-6CIDR (OVS-6CIDR, $n=117$ ). A total of 128 cows were not included in the study due to unclear vaginal discharge at the time of TAI $(n=121)$ and lost CIDRs during the protocols $(n=7)$.

Cows in the OVS group $(n=105)$ received the Ovsynch protocol, which included a GnRH treatment (GnRH-1) (Buserelin acetate, i.m., $10 \mu \mathrm{g}$, Receptal ${ }^{\circledR}$, Intervet, Turkey) followed by $\mathrm{PGF}_{2 \alpha}$ (Cloprostenol, $500 \mu \mathrm{g}$, i.m., Estrumate ${ }^{\mathbb{B}}$, CEVA-DIF, Turkey) 7 days later. A second GnRH treatment (GnRH-2) (Busere- 
lin acetate, $10 \mu \mathrm{g}$, Receptal ${ }^{\circledR}$ ) was administered $56 \mathrm{~h}$ after $\mathrm{PGF}_{2 \alpha}$, and all cows were inseminated at a fixed time (TAI) $16 \mathrm{~h}$ to $18 \mathrm{~h}$ after $\mathrm{GnRH}-2$ treatment.

The cows in the OVS-PGF group $(n=118)$ received the Ovsynch protocol with the difference being that two doses of $\mathrm{PGF}_{2 \alpha}$ (Cloprostenol, $500 \mu \mathrm{g}$, i.m., Estrumate ${ }^{\circledR}$ ) were used instead of using the traditional one dose of $\mathrm{PGF}_{2 \alpha}$. The $\mathrm{PGF}_{2 \alpha}$ administrations were performed $12 \mathrm{~h}$ apart on day 7 .

Cows in the OVS-7CIDR group $(\mathrm{n}=78)$ received exogenous progesterone (1.38 g progesterone, Controlled Internal Drug Release Device; CIDR ${ }^{\mathbb{R}}$, Pfizer, Turkey) in addition to the Ovsynch protocol, which included CIDR devices that were used for 7 days between GnRH-1 and $\mathrm{PGF}_{2 \alpha}$ of the Ovsynch protocol.

The cows in the OVS-6CIDR group $(n=77)$ received a CIDR application in addition to the Ovsynch protocol. However, the CIDR devices were administered for 6 days, and the devices were inserted one day after GnRH-1 administration and removed at the same time as the $\mathrm{PGF}_{2 \alpha}$ treatment, as in the OVS-7CIDR group.

The transrectal ultrasonographic evaluations were performed with a Honda HS 2000 equipped with a $7.5 \mathrm{MHz}$ transducer (Honda ${ }^{\mathbb{R}}$, Japan). Only cyclic cows (which had a corpus luteum at the beginning of the Ovsynch protocol) were included into the study. Cows were examined by ultrasonography on the day of GnRH-1 administration (to determine cyclicity and follicle sizes), 7 days later on the day of $\mathrm{PGF}_{2 \alpha}$ administration (to determine the ovulation response to GnRH-1), at the time of TAI (to determine the presence and size of the ovulatory follicle), and 7 days after TAI (to determine the ovulation response to GnRH-2). Ovulations in response to GnRHs were characterised by the disappearance of the responsive follicle and the appearance of a new corpus luteum (CL). Early ovulation (no follicle at the time of TAI) and no ovulation (no CL 7 days after TAI) were defined as non-synchronised cows. Pregnancy diagnoses were performed by ultrasonography at 31 days and 62 days after TAI.

Statistical analyses were conducted using the SAS software (Version 9.2; SAS Institute Inc., 2010). The data were evaluated using PROC LOGISTIC, PROC GLM and PROC FREQ in SAS. The statistical model included the effects of treatments, parity, days in milk (DIM), BCS, service number, average milk production, response to GnRH-1 and GnRH-2 of the Ovsynch, and follicle size at the time of TAI. PROC GLM was used to compare the differences among the groups for milk production, DIM, BCS and follicle size at the time of TAI among the groups. Chi-square results were obtained using the PROC FREQ procedure for independence tests between response to $\mathrm{GnRH}$ administrations and pregnancy per AI (P/AI, 31 and 62 days) among the groups. The LOGISTIC procedure was performed to determine the effect of covariant factors such as season, DIM, BCS, parity, service number, milk production and maximum follicle size at the time of TAI on P/AI (31 and 62 days). 


\section{Results}

General results

There were no differences among the groups with regard to BCS, milk production, DIM, service number, lactation number and maximum follicle size at the time of TAI. Thirty cows $(n=13$ in OVS, $n=10$ in OVS-PGF, $n=5$ in OVS-7CIDR, $\mathrm{n}=2$ in OVS-6CIDR) out of the 506 cows were not synchronised. CIDR-treated cows $(36.2 \%$; 88/243) had more $(\mathrm{P}=0.0001)$ unclear vaginal discharge at the time of TAI than those not treated with a CIDR $(12.9 \%$; 33/256).

\section{Effect of the protocols on synchronisation rate and $P / A I$}

Both the synchronisation rate (response to GnRH-2; 87.6\% in OVS, 91.5\% in OVS-PGF, 93.6\% in OVS-7CIDR and 97.4\% in OVS-6CIDR) and $\mathrm{P} / \mathrm{AI}$ at 31 days (48.6\% in OVS, 54.2\% in OVS-PGF, 52.6\% in OVS-7CIDR and $55.8 \%$ in OVS-6CIDR) and 62 days (42.9\% in OVS, 52.5\% in OVS-PGF, $48.7 \%$ in OVS-7CIDR, $49.3 \%$ in OVS-6CIDR) were similar among the groups. Additionally, pregnancy loss between 31 and 62 days was not different among the groups (Table 1).

\section{Effect of response to GnRH-1}

When all cows were evaluated, regardless of the treatment group, the cows responsive to $\mathrm{GnRH}-1$ had a higher $(\mathrm{P}=0.005)$ synchronisation rate $(95.4 \%$, $207 / 217)$ than the cows not responsive $(87.6 \%, 141 / 161)$, and P/AI at 31 days tended to be higher $(\mathrm{P}=0.07)$ in cows that responded $(56.7 \%, 127 / 217)$ as compared to cows that did not respond $(47.2 \%, 76 / 161)$. In addition, $\mathrm{P} / \mathrm{AI}$ at 62 days was higher $(\mathrm{P}=0.04)$ in cows that responded to GnRH-1 $(53.0 \%$; $115 / 217)$ compared to those that did not respond $(42.2 \% ; 68 / 161)$.

Although the percentage of cows that ovulated in response to GnRH-1 was similar among the groups (55.2\% in OVS; $56.8 \%$ in OVS-PGF; $55.1 \%$ in OVS7CIDR and $63.6 \%$ in OVS-6CIDR), the OVS-PGF group had a significantly higher $(\mathrm{P}=0.01)$ synchronisation rate in the cows responsive to GnRH-1 $(97.0 \% ; 65 / 67)$ as compared to those not responsive $(84.3 \%$; $43 / 51)$. Synchronisation rates were not different among the other groups with respect to cows responsive to GnRH-1 or not (Table 2). Although the synchronisation rate was higher in the OVS-PGF group, P/AI at 31 days was similar among groups. However, $\mathrm{P} / \mathrm{AI}$ at 62 days was different $(\mathrm{P}=0.04)$ in the OVS group between the cows responsive (51.7\%) and those not responsive to GnRH-1 (32.0\%) (Table 2). 
Table 1

Responses to GnRHs, pregnancy per $\mathrm{AI}(\mathrm{P} / \mathrm{AI})$ at 31 and 62 days, and embryonic loss in the different groups

\begin{tabular}{llllll}
\hline & OVS & OVS-PGF & OVS-7CIDR & OVS-6CIDR & P value \\
\hline Ovulation to GnRH-1 & $55.2 \%(58 / 105)$ & $56.8 \%(67 / 118)$ & $55.1 \%(43 / 78)$ & $63.6 \%(49 / 77)$ & 0.54 \\
Ovulation to GnRH-2 & $87.6 \%(92 / 105)$ & $91.5 \%(108 / 118)$ & $93.6 \%(73 / 78)$ & $97.4 \%(75 / 77)$ & 0.11 \\
P/AI at 31 days & $48.6 \%(51 / 105)$ & $54.2 \%(64 / 118)$ & $52.6 \%(41 / 78)$ & $55.8 \%(43 / 77)$ & 0.77 \\
P/AI at 62 days & $42.9 \%(45 / 105)$ & $52.5 \%(62 / 118)$ & $48.7 \%(38 / 78)$ & $49.3 \%(38 / 77)$ & 0.55 \\
Embryonic loss & $11.8 \%(6 / 51)$ & $3.1 \%(2 / 64)$ & $7.3 \%(3 / 41)$ & $11.6 \%(5 / 43)$ & 0.24 \\
\hline
\end{tabular}

Table 2

Synchronisation rate and pregnancy per AI at 31 and 62 days in cows according to their response to GnRH-1 in the different the groups

\begin{tabular}{|c|c|c|c|c|c|c|c|c|c|}
\hline & \multicolumn{3}{|c|}{ Synchronisation rate } & \multicolumn{3}{|c|}{ Pregnancy at 31 days } & \multicolumn{3}{|c|}{ Pregnancy at 62 days } \\
\hline & GnRH-1(+) & GnRH-1(-) & $P$ value & GnRH-1(+) & GnRH-1(-) & $P$ value & GnRH-1(+) & GnRH-1(-) & $P$ value \\
\hline OVs & $91.4 \%(53 / 58)$ & $83.0 \%(39 / 47)$ & 0.19 & $53.4 \%(31 / 58)$ & $42.6 \%(20 / 47)$ & 0.27 & $51.7 \%(30 / 58)$ & $32.0 \%(15 / 47)$ & 0.04 \\
\hline OVS-PGF & $97.0 \%(65 / 67)$ & $84.3 \%(43 / 51)$ & 0.01 & $56.7 \%(38 / 67)$ & $51.0 \%(26 / 51)$ & 0.54 & $53.7 \%(36 / 67)$ & $51.0 \%(26 / 51)$ & 0.77 \\
\hline OVS-7CIDR & $95.3 \%(41 / 43)$ & $91.4 \%(32 / 35)$ & 0.48 & $60.5 \%(26 / 43)$ & $42.9 \%(15 / 35)$ & 0.12 & $58.0 \%(25 / 43)$ & $37.1 \%(13 / 35)$ & 0.07 \\
\hline OVS-6CIDR & $98.0 \%(48 / 49)$ & $96.4 \%(27 / 28)$ & 0.68 & $57.1 \%(28 / 49)$ & $53.6 \%(15 / 28)$ & 0.76 & $49.0 \%(24 / 49)$ & $50.0 \%(14 / 28)$ & 0.93 \\
\hline $\mathrm{P}$ value & 0.38 & 0.21 & & 0.92 & 0.70 & & 0.84 & 0.20 & \\
\hline
\end{tabular}




\section{Discussion}

In the present study, we aimed to evaluate the effects of three different treatments on the optimisation of synchronisation during the Ovsynch protocol in cyclic lactating dairy cows. The success of the Ovsynch protocol dramatically depends on the responses to the hormones used in the protocol. With respect to the response to GnRH administrations, fertility is better in cows that respond to the GnRH-1 in the Ovsynch protocol compared to those cows that not respond (Vasconcelos et al., 1999; Moreira et al., 2001; Bello et al., 2006; Galvao and Santos, 2010; Keskin et al., 2010). In recent studies, the ovulatory response to GnRH-1 was between $45 \%$ and $75 \%$ (Bello et al., 2006; Galvao and Santos, 2010; Keskin et al., 2010). Similarly, our results showed that the response to GnRH-1 was between 55\% and 64\%. It is aimed to increase the ovulation rate in response to GnRH-1 in the OVS-6CIDR group by inserting a CIDR one day after GnRH-1 administration because progesterone concentrations after CIDR insertions decrease ovulation in response to $\mathrm{GnRH}$ administration (Galvao et al., 2004). Our results showed a numerical increase (7\%) in response to GnRH-1 in the OVS-6CIDR group and that the administration of exogenous progesterone one day after GnRH-1 did not increase the response to GnRH-1 in cyclic lactating dairy cows. In most of the studies (Vasconcelos et al., 1999; Moreira et al., 2001; Bello et al., 2006; Galvao and Santos, 2010; Keskin et al., 2010), higher ovulation rates to GnRH-1 increase synchronisation rate (response to GnRH-2) and pregnancy rate in lactating dairy cows because of its positive effect on both luteal and follicular responses to subsequent $\mathrm{PGF}_{2 \alpha}$ and GnRH-2 treatments of the Ovsynch protocol. Similar to previous studies (Vasconcelos et al., 1999; Moreira et al., 2001; Bello et al., 2006; Keskin et al., 2010), cows that responded to GnRH-1 had a higher $(\mathrm{P}=0.005)$ synchronisation rate (response to $\mathrm{GnRH}-2)$ compared to cows that did not respond, regardless of the treatments in our study.

Synchronisation rates in previous studies were between $75 \%$ and $95 \%$ (Bello et al., 2006; Brusveen et al., 2009; Galvao and Santos, 2010; Keskin et al., 2010). Similarly, in the current study, synchronisation rates ranged from $87 \%$ to $97 \%$. Brusveen et al. (2009) reported similar synchronisation rates between the cows treated with and without an extra dose of $\mathrm{PGF}_{2 \alpha}(89 \%$ and $90 \%$, respectively). Additionally, the synchronisation rates were not affected by CIDR administration during the Ovsynch protocol in previous studies (Kim et al., 2003; Galvao et al., 2004). Thus, it was found that a double dose of $\mathrm{PGF}_{2 \alpha}$ or CIDR administrations ( 6 or 7 days) had no effect on increasing the synchronisation rate during the Ovsynch protocol.

Synchronisation rates were evaluated in response to GnRH-1. In the OVSPGF group, cows that responded to GnRH-1 $(97 \%)$ had a higher $(\mathrm{P}=0.01)$ synchronisation rate compared to cows that did not respond (84\%). This difference may have originated from the expected effect of using double doses of $\mathrm{PGF}_{2 \alpha}$ on 
the cows that responded to GnRH-1, which means that there was a new CL at the time of $\mathrm{PGF}_{2 \alpha}$ (potentially less responsive to one dose of $\mathrm{PGF}_{2 \alpha}$ ). Although there were no differences among the groups, the synchronisation rates in the cows that did not respond to GnRH-1 in the CIDR-treated groups were considerably higher ( $\sim 94 \%)$ compared to the groups where CIDR was not used ( $\sim 84 \%)$. This finding could be due to the positive effect of progesterone supplementation on cows that had regressing CL during the Ovsynch protocol.

In the present study, the average diameter of the dominant follicles at the time of AI was not different among the groups ( $\sim 15 \mathrm{~mm}$ diameter). This result was similar to the data reported by Galvao et al. (2004), where the follicle diameters at the time of AI were not different whether or not the cows received a CIDR.

The treatments in the present study had no effect on pregnancy rates at both 31 and 62 days. Similar to our results, Brusveen et al. (2009) reported that there was no improvement in fertility due to additional $\mathrm{PGF}_{2 \alpha}$ even when there was increased efficiency of luteolysis in their study. In our study, even with the cows evaluated according to their response to GnRH-1, pregnancy rates were similar between the OVS and the OVS-PGF group. However, our results contrast with the results of most authors, who reported higher pregnancy rates after using progesterone integration during Ovsynch compared with the Ovsynch protocol alone (Kim et al., 2003; El-Zarkouny et al., 2004; Stevenson et al., 2006; Pancarci et al., 2008). Pancarci et al. (2008) reported higher pregnancy rates in cows administered a CIDR one day after GnRH-1 for 6 days during Ovsynch compared with the cows administered a CIDR with GnRH-1 for 7 days during Ovsynch and the cows that received only Ovsynch. The author argued that these results of a high pregnancy rate after 6-day CIDR administration may be attributable to a better follicle turnover during the Ovsynch protocol, leading to high pregnancy rates and lower embryonic losses. In our study, there was no difference in ovulation in response to GnRH-1 or in pregnancy rates between 7- and 6day durations of CIDR administration. Stevenson et al. (2006) reported that cows having low serum progesterone before $\mathrm{PGF}_{2 \alpha}$ administration, irrespective of whether they were cycling or not, had higher pregnancy rates when treated with a CIDR insert. Because cyclic cows were evaluated in the current study, we assumed that the cows that did not respond to GnRH-1 would utilise the CIDR integration and have higher pregnancy rates. However, there was no improvement in fertility in CIDR-treated cows that did not respond to GnRH-1. The pregnancy rates at 62 days in the OVS-7CIDR group tended to be different $(\mathrm{P}=0.07)$ between cows responsive to GnRH-1 and those not responsive, while there was no difference between those cows in the OVS-6CIDR group. We also found a significant difference $(\mathrm{P}=0.04)$ in 62-day pregnancy rates in the OVS group between cows that responded to GnRH-1 and those which did not respond. In harmony with these results, Pancarci et al. (2008) reported that cows receiving 
Ovsynch alone had a lower chance of becoming pregnant at 60 days than those who received a 6-day-long CIDR administration during Ovsynch. This difference in the OVS group may be attributable to the increased proportion of cows with regressing CL, which may be due to low progesterone levels before AI, leading to higher embryonic loss; however, there was no difference in cows of the OVSPGF group.

In conclusion, regardless of the treatments, increasing the response to GnRH-1 enhanced synchronisation rate and fertility. Addition of a second PGF $_{2 \alpha}$ or CIDR (either 7- or 6-day) treatment to the Ovsynch protocol did not improve either synchronisation or pregnancy rates.

\section{Acknowledgements}

The authors thank TARFAS Co. (Bursa, Turkey) for the use of their herd and facilities. Support was also provided by the Scientific and Technological Research Council of Turkey (TUBITAK), grant no. TOVAG 107O227. Gulnaz Yilmazbas-Mecitoglu was supported by the TUBITAK-BIDEB International Postdoctoral Research Fellowship Programme.

\section{References}

Bello, N. M., Steibel, J. P. and Pursley, J. R. (2006): Optimizing ovulation to first GnRH improved outcomes to each hormonal injection of Ovsynch in lactating dairy cows. J. Dairy Sci. 89, 3413-3424.

Brusveen, D. J., Souza, A. H. and Wiltbank, M. C. (2009): Effects of additional prostaglandin $F_{2 \alpha}$ and estradiol-17 $\beta$ during Ovsynch in lactating dairy cows. J. Dairy Sci. 92, 1412-1422.

El-Zarkouny, S. Z., Cartmill, J. A., Hensley, B. A. and Stevenson, J. S. (2004): Presynchronization of estrous cycles before Ovsynch and progesterone in dairy cows. J. Dairy Sci. 87, 1024-1037.

Ferguson, J. D., Galligan, D. T. and Thomsen, N. (1994): Principal descriptors of body condition score in Holstein cows. J. Dairy Sci. 77, 2695-2703.

Galvao, K. N. and Santos, J. E. P. (2010): Factors affecting synchronization and conception rate after the Ovsynch protocol in lactating Holstein dairy cows. Reprod. Domest. Anim. 45, 439-446.

Galvao, K. N., Santos, J. E. P., Juchem, S. O., Cerri, R. L. A., Coscioni, A. C. and Villansenor, M. (2004): Effect of addition of a progesterone intravaginal insert to a timed insemination protocol using estradiol cypionate on ovulation rate, pregnancy rate and late embryonic loss in lactating dairy cows. J. Anim. Sci. 82, 3508-3517.

Gumen, A., Guenther, J. N. and Wiltbank, M. C. (2003): Follicular size and response to Ovsynch versus detection of estrus in anovular and ovular lactating dairy cows. J. Dairy Sci. 86, 3184-3194.

Keskin, A., Yilmazbas-Mecitoglu, G., Gumen, A., Karakaya, E., Darici, R. and Okut, H. (2010): Effect of hCG vs. GnRH at the beginning of the Ovsynch on first ovulation and conception rates in cyclic lactating dairy cows. Theriogenology 74, 602-607.

Kim, I. H., Suh, G. H. and Son, D. S. (2003): A progesterone-based timed AI protocol more effectively prevents premature estrus and incomplete luteal regression than Ovsynch protocol in lactating Holstein cows. Theriogenology 60, 809-817. 
Martins, J. P. N., Policelli, R. K., Neuder, L. M., Raphael, W. and Pursley, J. R. (2010): Effects of cloprostenol sodium at final prostaglandin $\mathrm{F}_{2 \alpha}$ of Ovsynch on complete luteolysis and pregnancy per artificial insemination in lactating dairy cows. J. Dairy Sci. 94, 2815-2824.

Moreira, F., Orlandi, C., Risco, C. A., Mattos, R., Lopes, F. and Thatcher, W. W. (2001): Effects of presynchronization and bovine somatotropin on pregnancy rates to timed artificial insemination protocol in lactating dairy cows. J. Dairy Sci. 84, 1646-1659.

National Research Council (2001): Nutrient Requirements of Dairy Cattle. Seventh revised Edition. National Academy press, Washington, D.C.

Pancarci, S. M., Gurbulak, K., Gungor, O., Demiral, O. and Thatcher, W. W. (2008): Integration of CIDR in timed artificial insemination protocol in lactating dairy cows. Reprod. Domest. Anim. 43 (Suppl 3), 57.

Pursley, J. R., Mee, M. O. and Wiltbank, M. C. (1995): Synchronization of ovulation in dairy cows using $\mathrm{PGF}_{2 \alpha}$ and $\mathrm{GnRH}$. Theriogenology 44, 915-923.

SAS Institute Inc. (2010): SAS/Access ${ }^{B} 9.2$ for Relational Databases: Reference. Fourth edition. SAS Institute Inc., Cary, NC, USA.

Stevenson, J. S., Pursley, J. R., Garverick, H. A., Fricke, P. M., Kesler, D. J., Ottobre, J. S. and Wiltbank, M. C. (2006): Treatment of cycling or noncycling lactating dairy cows with progesterone during the Ovsynch. J. Dairy Sci. 89, 2567-2578.

Vasconcelos, J. L. M., Silcox, R. W., Rosa, G. J. M., Pursley, J. R. and Wiltbank, M. C. (1999): Synchronization rate, size of the ovulatory follicle, and pregnancy rate after synchronization of ovulation beginning on different days of the estrous cycle in lactating dairy cows. Theriogenology 52, 1067-1078. 